\title{
Quando plagiar é escrever a história: Alphonse de Beauchamp entre a historiografia antiga e moderna
}

Flávia Varella*

Medeiros, Bruno Franco. Plagiário, à maneira de todos os historiadores. Jundiaí: Paco Editorial, 2012.

No Brasil, poucas áreas de estudo vêm crescendo atualmente com o mesmo vigor que a história da historiografia. Em um passado não muito distante, eram raros os estudos que tinham como foco principal de suas análises as narrativas, os gêneros, as linguagens ou outras organizaçóes textuais presentes nos trabalhos históricos. O livro, recentemente lançado, de Bruno Franco Medeiros, Plagiário, à maneira de todos os historiadores, é certamente um dos frutos desse novo cenário dos estudos em história da historiografia. Inicialmente pensado como dissertação de mestrado, defendida em 2011 no Programa de Pós-Graduação em História Social da Universidade de São Paulo, o livro tem por objetivo central "traçar as especificidades da narrativa histórica empreendida por [Alphonse de] Beauchamp", e analisar "de que modo [essa narrativa] se relacionava com outras que se desenvolveram no mesmo contexto" (p. 17). Assim, o leitor é guiado através de algumas discussóes que se colocavam sobre as formas, mais ou menos adequadas, para a escrita histórica e os embates que figuravam na legitimação e construção dos estudos históricos nas primeiras décadas do século XIX.

Seja no contexto de recepção brasileiro ou francês, Beauchamp teve seu nome constantemente atrelado ao adjetivo plagiário. Nascido na década de 1760, escreveu suas obras na capital parisiense no decorrer dos primeiros trinta anos do século XIX, falecendo em 1832. A hipótese central de Medeiros é que o rótulo de plagiário foi possível devido à rejeição, por parte dos críticos de Beauchamp, de alguns parâmetros de escrita da história, notadamente herdeiros da tradição clássica antiga, empregados em sua narrativa. Isso significa dizer que Beauchamp entendia a história como ação que deveria transcorrer diante dos olhos para melhor instruir seu leitor sobre os fatos do passado. O historiador deveria prezar por um estilo colorido, vivaz e repleto de detalhes, que compunham a verdadeira alma da história (p. 26). Complementarmente, o valor da história estava em sua força pedagógica e na sua capacidade de mostrar elementos que possibilitassem o entendimento do presente e a previsão do futuro. Beauchamp considerava que a história era muito mais do que um simples levantamento de fatos e datas: ela deveria instruir os homens por meio dos bons e maus exemplos (p. 28-29). Pensava

Resenha - DOI - http://dx.doi.org/10.1590/2237-101X01402700X 
que sua missão "era condenar eternamente à estima ou ao esquecimento, ao desprezo ou à admiração, aqueles homens que desolaram ou consolaram o universo" (p. 48).

Tomando por base as reflexóes de François Hartog, Medeiros enfatiza a existência sincrônica de dois regimes de historicidade divergentes no início do século XIX francês, buscando mapeá-los através do tratamento dado ao passado pela sociedade e da consciência que ela produziu de si mesma, ou seja, da sua historicidade (p. 16). De forma sucinta, é possível dizer que a consequência mais imediata da existência de dois regimes de historicidade para a história da historiografia é a prefiguraçáo de, igualmente, dois modelos de escrita da história - um antigo/ clássico e outro moderno - baseados em diferentes epistemologias. Infelizmente, para sua fortuna crítica, Beauchamp encontrava-se alinhado com o regime de historicidade (clássico) em constante perda de prestígio e, assim, seus oponentes se multiplicavam na medida em que uma nova história de sua autoria era publicada. Essas críticas, contudo, não indicam a existência de "uma defasagem intelectual ou mesmo o desconhecimento dessas novas formas" de escrita por sua parte (p. 18).

Com o avançar do século XIX, a condenação dos parâmetros de validade e composiçâo empregados pela historiografia clássica foi ganhando espaço rapidamente, sobretudo no que diz respeito à sustentação da história como efetividade da performance, à falta de aparato crítico e erudito e à invenção retórica. Não se admitia mais, por exemplo, a inserção de discursos diretos, que antes au- xiliavam na memorização e fixação da trama, pois sendo fabricados pelo historiador eram naturalmente mentirosos (p. 135-138). A verdade histórica sofreu uma grande mudança ao ser contraposta ao estilo, um embuste desvirtuador da verdade fatual. Aliado a isso, a escrita da história contemporânea, tão cara aos historiadores clássicos, também foi sendo impossibilitada pela alegaçáo de falta de distanciamento e imparcialidade, inerentes a qualquer história que tratasse do presente. À história restava o passado, nu e cru.

Ao defender a importância do estilo e a centralidade do presente, Beauchamp seria um historiador mais alinhado com os parâmetros de escrita da historiografia clássica. Como esclarece Medeiros, Beauchamp considerava primordial a escrita da história contemporânea, pois era através do seu estudo que despontava a possibilidade de entendimento do passado e do futuro e, consequentemente, do verdadeiro funcionamento da natureza humana. Além disso, o presente poderia ser investigado com maior precisão, na medida em que o historiador teria à disposição testemunhas dos acontecimentos e suas memórias. As testemunhas oculares dos eventos ocorridos em um passado remoto não existiam mais, dificultando a investigação dos detalhes. A qualidade da informação passível de ser recolhida sobre a história do presente era muito melhor se comparada à fragmentada história do passado (p. 30). Os documentos oficiais, para Beauchamp, eram apenas o "esqueleto da história", e "a substância e as cores nós adquirimos das memórias particulares, nas relaçốes confi- 
denciais, nas notas comunicadas por pessoas cujo testemunho é irrecusável, e tendo visto eles mesmos os eventos" (p. 40-41). As memórias, assim, eram onde a verdadeira essência da história poderia ser resgatada, onde o historiador iria buscar as cores da narrativa e encontrar os "detalhes importantes que nenhum outro documento público poderia suprir" (p. 41).

A combinação de uma escrita historiográfica que lidava com o presente e, consequentemente, com fontes contemporâneas e que privilegiava ressaltar as cores da história, como mostra Medeiros, certamente contribuiu para a caracterizaçáo de Beauchamp como plagiário. Beauchamp não se considerava um erudito e pensava que seria charlatanismo de sua parte inserir notas de citação e de comentários em seu texto; notas essas que, além de tudo, eram inadequadas ao seu estilo de escrita histórico (p. 129). Contudo, qualquer um que desejasse escrever história nas primeiras décadas do século XIX era impelido a citar de modo preciso as informaçóes retiradas de obras alheias, de outra forma seria considerado um plagiário.

Entre os séculos XVII e XVIII, argumenta Medeiros, o conceito de plágio passou por algumas mudanças fundamentais. No século XVII a palavra plágio não continha significado pejorativo ligado à cópia de pesquisa de terceiro, sendo indicativa de imitação. Grande parte do que era produzido até então poderia ser considerada imitação na medida em que existiam os lugares comuns, revisitados constantemente, que serviam de inspiração aos autores. Mas no início do século XVIII, a semântica de plágio foi descolada da de imitação e surgiu reformulada como "a ação de retirar de um autor (particularmente moderno e nacional, o que agravaria o delito) os trechos de uma obra de invençáo, uma ideia nova e ainda pouco conhecida e traços de um ou vários pensamentos" (p. 117). Essa foi, por diversas vezes, a acusação que assombrou Beauchamp.

E sob a égide de plagiário Beauchamp escreveu a Histoire du Brésil, publicada na França, em 1815. Chamava a sua atenção que, até aquele momento, nenhuma história geral completa do Brasil tivesse sido publicada, existindo apenas informaçóes esparsas e inexatas sobre esse território (p. 56-57). A sua Histoire, argumentava, viria completar essa lacuna ao realizar em suas primeiras páginas uma síntese da história de Portugal desde 1139 até os Descobrimentos e, depois, ao abordar de perto a história do Brasil até meados de 1810. Se boa parte das críticas elencadas em relação às histórias escritas anteriormente por Beauchamp estava relacionada à escrita da história contemporânea, era de se esperar que essa história tivesse uma melhor recepção, coisa que, de fato, parece náo ter acontecido. Como salienta Medeiros, "apesar de a Histoire du Brésil ter como objetivo de representação um passado mais remoto (...) sua estrutura tinha como eixo principal os acontecimentos daquele momento". Dessa forma, Beauchamp não fugia completamente da história contemporânea e, consequentemente, das críticas, ao ter seu foco narrativo sobre "a transmigraçáo da Corte para o Brasil em 1808 e as consequências daquele acontecimento para a história do Império português, com grande 
acento para o lugar ocupado pelo Brasil naquele momento" (p. 59).

Medeiros também póe à mostra o curioso interesse que um grupo de portugueses teve pela tradução da Histoire du Brésil. Em 1817, o tipografo Desidério Marques Leão, com Pedro José Figueiredo, responsável pelas anotações e correçôes, e Pedro Ciryaco da Silva, um dos tradutores, iniciaram a empreitada de tradução da obra, com o financiamento do governo português, e publicaram a História do Brasil, em onze volumes. Os seis primeiros volumes são a tradução da história de Beauchamp, com anotaçóes que visavam à correção de algumas informaçóes. Os outros cinco volumes continuam a Histoire do seu fim (1810) até a atualidade, prática não incomum na época. $\mathrm{Na}$ análise de Medeiros, esse esforço de tradução estava relacionado às medidas "para colocar em prática o projeto de regeneração portuguesa” (p. 63). Marques Leão considerava que Beauchamp havia presenteado "os Portugueses, e o mundo culto com uma história sem contradição original, e a primeira até aquele tempo mais bem coordenada, e interessante particularmente aos Portugueses (...)”. A história do Brasil interessava aos portugueses na medida em que se mostrava como a história da regeneração de Portugal (p. 64).

Esse intercâmbio letrado entre Portugal e França, salienta Medeiros, perdurou também em solo brasileiro por longas décadas com a missão francesa, a proximidade entre o Instituto Histórico e Geográfico Brasileiro (IHGB) e o Institut Historique de Paris, entre outros movimentos que buscavam estreitar os laços civilizacionais entre Brasil e
França no intuito de "construir uma imagem do Brasil como uma nova nação que nascia com os tempos modernos, acertando seus passos com a grande narrativa de progresso que se forjava na Europa” (p. 106).

A justificativa de ineditismo feita por Beauchamp e o interesse dos lusos na tradução da obra estariam perfeitamente explicados se não existisse a History of Brazil de Robert Southey. Em 1810, Southey publicou o primeiro volume de sua história e em 1817 , mesmo ano em que iniciou o projeto de Marques Leão, saía o segundo volume da obra. Isso significa que, de fato, existia uma obra mais sólida, do ponto de vista documental e de pesquisa, que também pretendia, como a Histoire du Brésil, cobrir a lacuna existente em relação à escrita da história geral brasileira (Robert Southey. History of Brazil, v. 1, s.p.). O que ainda fica por ser investigado é a falta de interesse do governo português na tradução da história de Southey, que só ganhou uma edição em língua portuguesa em 1852, por esforços brasileiros.

Além disso, a acusação de plágio por parte de Beauchamp, desta vez, remete justamente à History of Brazil de Southey. Em 3 de outubro de 1815, logo após a publicação da Histoire du Brésil, Southey informava a um de seus amigos que havia adquirido um exemplar quando estava na Bélgica e, como não era difícil de prever por causa da fama de plagiário de Beauchamp, tratava-se de um roubo intelectual. Exceto o capítulo introdutório, todo o resto consistia em tradução de sua história, inclusive as referências e fontes haviam sido retiradas da History of Brazil. Southey acreditava que a história de 
Beauchamp facilmente cairia em descrédito, pois se tratava claramente de uma composição não original. Inclusive cogitou a hipótese de escrever uma carta ao jornal Courier expondo o plágio, mas acabou desistindo da ideia e contentou-se com a réplica publicada no prefácio do segundo volume da History of Brazil.

Beauchamp consideraria essa acusação de plágio de Southey como infundada, já que, como aponta Medeiros, entendia como plagiário "aquele que se apropria de um texto ou de parte dele, sem fazer menção ao autor" (p. 126). Ele certamente havia, nas primeiras páginas de sua história, mencionado a consulta à obra de Southey. Contudo, a compilação realizada não poderia ser justificada com esse simples gesto, pois a escrita da história nas primeiras décadas do século XIX estava diretamente ligada à originalidade e às técnicas de verificação da informação. Beauchamp acreditava firmemente que suas histórias não eram plágios, pois, além de sinalizar o material utilizado, seu estilo de escrita estava inscrito nelas. Como sugere Medeiros, "a convivência (não pacífica) entre a demanda por uma história crítica - baseada em uma pesquisa rigorosa, que exigiu do historiador o levantamento de provas históricas mais eficazes para comprovar sua narrativa - e antigas formas baseadas na eloquência e na maneira como os antigos escreviam história, ocasionou esse tipo de querela entre aqueles que escreviam história na França nas primeiras décadas no século XIX” (p. 144).

Os historiadores da Antiguidade Clássica, ao menos no que se refere aos relatos que sobreviveram de uma forma mais completa, não realizavam narrativas concorrentes, ou seja, quando se debruçavam sobre a história raramente escreviam sobre um período ou assunto já abordado. A história só precisava de um historiador para não ser devorada pelo tempo. Contudo, junto com a profissionalização do campo, o desenvolvimento de métodos e técnicas específicas e a convicção de que o passar do tempo era um aliado para a escrita de uma história mais acurada, também se tornou pungente a necessidade constante de reescrita do passado. Não era mais suficiente, e nem desejado, a publicação de histórias compilatórias, mas, sim, da crítica e refinamento do que já havia sido escrito.

Ao longo do Plagiário, à maneira de todos os historiadores, Medeiros aponta, diversas vezes, a existência do modelo antigo de escrita da história e sua disponibilidade narrativa aos escritores do século XIX. Contudo, parece isento de dúvida que não existia um modelo de escrita da história antigo, e muito menos moderno, mas diversas combinaçôes de gêneros e linguagens que resultavam em uma composição histórica. É difícil pensar e, além disso, empobrece o entendimento da historiografia que Heródoto fizesse parte do mesmo modelo antigo de escrita da história que Tácito. Apesar de o debate iniciado por Medeiros contribuir de forma indiscutível não apenas para o esclarecimento da historiografia produzida por Beauchamp, mas, de forma mais ampla, para a compreensáo mais apurada das disputas historiográficas vigentes no início do século XIX, acredito que a discussão ganharia em complexidade ao tentarmos não pensar dicotomicamente 
em modelo historiográfico antigo e moderno, mas em como os gêneros, históricos ou não, e as linguagens disponíveis para utilização e combinação entre si contribuíram para a formação do que chamamos vulgarmente de historiografia antiga e moderna.

Uma citação, em especial, apresentada por Medeiros é bastante esclarecedora dessa diferença. Ao afirmar, de forma bastante livre, que existiriam, ao menos, três modelos de escrita da história disponíveis na França de início do século XIX, cita as palavras de Conrad Malte-Brun “(...) ao lado da história oratória, pode existir outros gêneros menos brilhantes, mas todavia, muito úteis, a saber: a história filosófica e a história erudita" (p. 154-155). Apesar de Malte-Brun náo tratar de modelos, mas de gêneros, Medeiros toma-os por sinônimos. Pensando em outros termos, existiria uma multiplicidade de gêneros ao longo do século XVIII e início do XIX, como a história política, o antiquariato, a história conjetural, história religiosa, história dos costumes, história da ciência, história da literatura, biografia, memória, o romance, entre tantos outros passíveis de serem empregados na composição histórica (Mark Salber Phillips. Reconsiderations on history and antiquarianism: Arnaldo Momigliano and the historiography of eighteenth-century Britain, p. 299). Por outro lado, e também evitando a dicoto- mia antigo e moderno, é possível analisar a narrativa histórica, um gênero de escrita em si, como articuladora de uma gama de linguagens - o tacitismo, republicanismo, humanismo comercial etc. - que constroem a sua teia argumentativa (John Pocock. Linguagens do ideário político, p. 23-62).

Falar da existência de um modelo antigo e moderno de escrita da história tornou-se quase um mote dentro dos estudos em história da historiografia, o que, de certa forma, deve-se muito à dicotomia apresentada por Reinhart Koselleck entre o conceito antigo e o moderno de história (historia/Historia. Madri: Trotta, 2004) e aos estudos de Arnaldo Momigliano (em especial As raizes clássicas da historiografia moderna. Bauru: Edusc, 2004). Talvez seja a hora de revê-los como pano de fundo explicativo de um cenário historiográfico que, apesar das peculiaridades nacionais, segue uma tendência universal. O livro de Medeiros, nesse sentido, é um passo importante no entendimento mais detalhado da historiografia e das interpretaçóes produzidas por estrangeiros da história brasileira, dando um passo à frente para a consolidação da história da historiografia como campo que merece a atençáo dos historiadores.

* Doutoranda em história pela Universidade Federal do Rio Grande do Sul. Porto Alegre, RS, Brasil. E-mail: flavia_varella@hotmail.com. 